\title{
Smart Agriculture to Measure Humidity, Temperature, Moisture, Ph. and Nutrient Values of the Soil using IoT
}

\author{
Asadi Venkata Mutyalamma, Gopisetty Yoshitha, Althi Dakshyani, Bachala Venkata Padmavathi
}

\begin{abstract}
Smart Agriculture now-a-days reducing various problems in farming. Farmers get required information and relative data to monitor the plants growth by the use of "INTERNET OF THINGS (IOT)", which connects the different sensors, actuators and other embedded devices. To provide quality crops based on soil nutrient level and its moisture content along with Ph. factor, also been maintained. Hence, in this project all those parameters are detected and controlled with the help of micro controller. Humidity sensor to detect the moisture content, where colour sensor is used to determine the percentage of soil nutrients $\left(\mathrm{N}_{2}, \mathrm{P} 4 \mathrm{\& K}\right)$. It will analyse soil nutrient content present in soil at real time and $P h$. sensor is used to determine the $P h$ value of the soil. Monitrring of these it provides the proper fertility to the soil depending upon the soil nutrients. GSM is used to display the information to the farmers. Thus it reduces the growing of husk in terms of wastage and thereby getting good quality and healthy crops.

Keywords: Internet of Things, Soil sensor, Ph sensor, Moisture sensor, Colour sensor and embedded system.
\end{abstract}

\section{INTRODUCTION}

$\mathrm{P}_{1}$ ants [5] play a crucial role in the survival of human life in such a way that they provide oxygen when we need it. Meanwhile, Agriculture is also a beneficiary factor for living beings because it forms the basis for food security. To get a better crop, the most important things that should be there in the land that has accurate fertilizer, better irrigation facilities and best methods for cultivation. An adequate amount of fertilizer can help plants to produce better yield and quantity to meet the needs of world economy that is increasing the raise in need of food and its production. Over $58 \%$ of the rural population depends on agriculture for their livelihood and its export constitutes $10 \%$ of the country's exports.so, the farmers and even the nation's economy will be reduced if there are no proper yields due to lack of knowledge of the soil nature and unavailability of water. Therefore, the Indian government must take precautions for better and profitable agriculture.

Revised Manuscript Received on May 25, 2020.

* Correspondence Author

Asadi Mutyalamma*, Assistant Professor, Department of Electronics and Communication Engineering, Bapatla Women's Engineering college, Bapatla, Andhra Pradesh, India.

Gopisetty Yoshitha, Department of Electronics and Communication Engineering, Bapatla Women's Engineering College, Bapatla, Andhra Pradesh, India.

Althi Dakshyani, Student, Department of Electronics and Communication Engineering, Bapatla Women's Engineering College, Bapatla, Andhra Pradesh, India.

BachalaVenkata Padmavathi, Student, Department of Electronics and Communication Engineering, Bapatla Women's Engineering College, Bapatla, Andhra Pradesh, India.

(C) The Authors. Published by Blue Eyes Intelligence Engineering and Sciences Publication (BEIESP). This is an open access article under the CC BY-NC-ND license (http://creativecommons.org/licenses/by-nc-nd/4.0/)
This project is a smart farming system based on IoT (Internet of Things) which has brought changes to every field of common man's life by making everything smart and intelligent. This project aims to innovate a smart IOT based agriculture guides the farmers by the updated data like Temperature, Moisture, Humidity, $\mathrm{pH}$ value and Nutrient detection of soil which will enable them to do smart farming and increases the overall productivity of crops. Thus, it makes the farmers yield good profits and produce crops. This project proposed using Arduino technology, a breadboard with different sensors and live data will feed to the Farmers mobile phones via, SMS.

\section{LITERACY SURVEY}

Most of the farmers[4] and land managers have the soil analyzed for finding Nutrients, Temperature and other parameters of the soil. Throughout the 1990s, people used to test and analyze the soil physically to measure the soil parameters. It is very difficult and time taking process and also not accurate. At present, IOT technology helps to monitor and analyze the basic parameter of the soil based on the sensing. Soil consists of weathered rock fragments, organic matters, and Minerals. It provides a "Home" for countless microorganisms and plant roots. Its depth varies from few inches to several feet. Soil provides water, Nutrients, suitable minerals and physical support for the plants. Roots located in the soil are primary resources for getting nutrients from the dead cells, tissues and minerals present in the soil. Carbon dioxide $\left(\mathrm{CO}_{2}\right)$ and water $\left(\mathrm{H}_{2} \mathrm{O}\right)$ are the basic sources for the life of plant.

This project evaluated the variations of wired sensor networks and their potential for the advancement of various agricultural application improvements. It features the main agricultural and cultivating applications and examines the appropriateness of wired sensor networks towards improved performance and profitability[3].

Through sensor networks, agriculture can ome easier, can be attached to the Internet of things, which enables us to make connections among agronomists, farmers, and crops instead of the geographical differences. With the help of this methodology which gives real-time data through message about the lands and crops that will enable farmers to make the right decisions.

The significant advantage is an implementation of Wired Sensor Network will reduce the usage of

Water fertilizers maximizing the yield of the crops and further will help in experimenting with the weather conditions of the field.

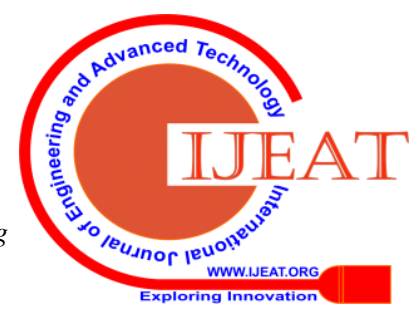


It fluctuates Control of the entire deployed framework in a single system. Which will make it simple to deal with and better understanding the results by users. Just as it keeps the farmer updated by the notifications for almost every related event that happens in the field. It mainly focuses on the sensors.

Our system using Arduino and various sensors to monitor the different stages of plant cropping like moisture, Temperature, Humidity, pH value and Nutrients of the soil. In this, we are using the Arduino Uno model with the GSM module. It helps the processing, transmission, and reception of data between sensors and the Microcontroller (ATMEGA3208P). The main purpose of this project is to lower the cash and farming fee and also save electricity, protecting the soil from harmful chemicals and fertilizers, reducing the wastage of water and increasing the productivity of crop.

\section{EXISTED SYSTEM}

Previously, Farmers take soil to the geological technicians who collect and analyse the soil samples to determine whether they are suitable for agricultural, developmental or Natural uses. Further, the concept of IOT is introduced in Agriculture. There are many devices introduced in the market that allows farmers to get information about the nature of the soil through mobile phones. These devices are having a huge influence on reducing costs and reduce the time[2]. Nutrients and acidic value of the soil plays a very vital role in the plant growth. Due to the ecological changes, the acidity and nutrient values of the soil are varying day by day because of this the plant growth is degrading. This existing system is limited to finding moisture, humidity, the temperature of the soil only.

\section{PROPOSED SYSTEM}

Our study is the extension of the existing system. As we are using the latest IOT technology, which helps in collecting information about conditions like moisture, temperature, $\mathrm{pH}$, nutrients value of the soil, of the field. Sensors like moisture, temperature, $\mathrm{pH}$, nutrients are used for the detection of the plant conditions and microcontrollers are used to control and automate the farm processing. GSM Module is used for sending and receiving the updated message through smartphones to the farmers with the ongoing conditions of his agricultural land using IOT at any time and any part of the world.

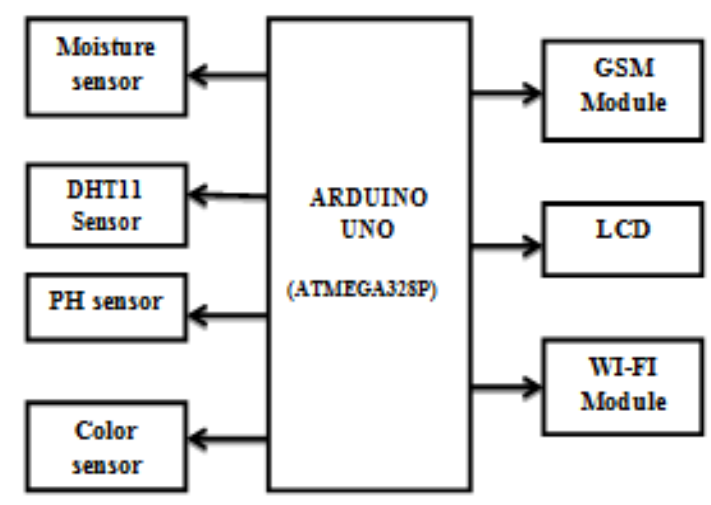

Fig 1: Block diagram of proposed system

\section{HARDWARE USED}

This project consists of many hardware components. This proposed technology helps to enable the different types of sensors through the communication with the Microcontroller in Arduino Uno. This helps the farmers how to select the best crop for their suitable soil.

\section{A. Arduino Uno}

Arduino Uno[7] is a microcontroller that is referred to as an actual mini-board. It has various types of pins i.e; analog and digital pins. There are 14 digital and 6 analog pins. Usually, it uses the power 7 to 12 volts for working through the USB cable.

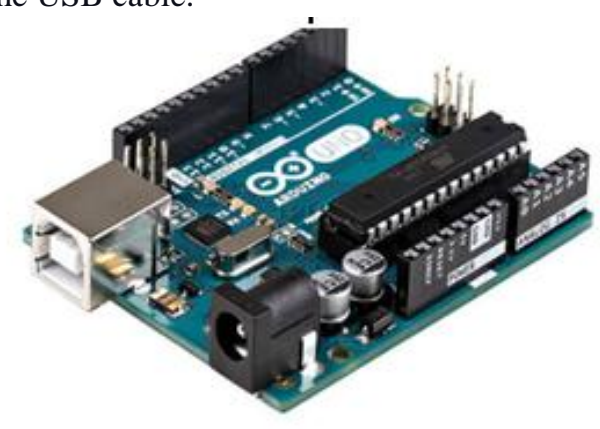

Fig 2: Arduino Uno

Soil Moisture Sensor:

This sensor is used to detect the moisture content in the soil for the better yielding of crops. If the soil has less water content then it automatically indicates that there is less water contamination. It has four pins. Among them, one pin is analog pin $\left(A_{0}\right)$ and one Digital pin $\left(D_{0}\right)[3]$.

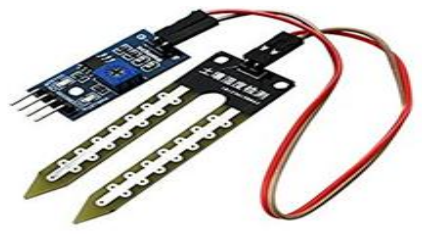

Fig 3: Soil Moisture Sensor

\section{B. DHT11 Sensor}

This sensor indicates the Humidity and Temperature of the soil. It helps the farmers to respond immediately according to the soil conditions. It consists of 3 pins. One of them are output pin and two pins are used to determine the analog readings of Temperature and Humidity.

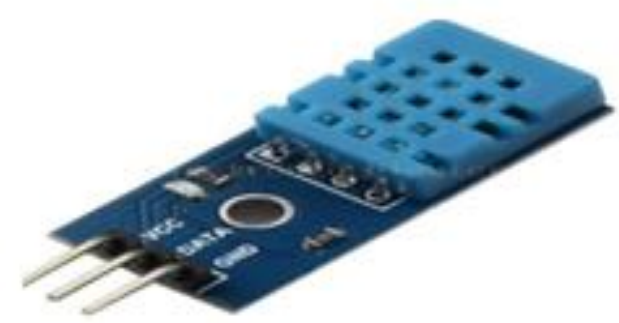

Fig 4: DHT11 sensor

Published By:

Blue Eyes Intelligence Engineering

Retrieval Number: D8940049420/2020@BEIESP

DOI: 10.35940/ijeat.D8940.069520

Journal Website: www.ijeat.org

\& Sciences Publication

(C) Copyright: All rights reserved. 


\section{C. pH Sensor}

$\mathrm{pH}$ (Potential Hydrogen)[9] meter is a device used to measure acidity and alkalinity levels in water, soil and photo chemicals. Basically $\mathrm{pH}$ meter consists of voltmeter attached to a $\mathrm{pH}$ responsive electrode it varies between the ranges of 0 to 14 .

The solutions having $\mathrm{pH}$ value between 0 to7 are acidic solutions with large concentration of hydrogen ions whereas solutions having $\mathrm{pH}$ value between 8 to14 have basic solutions with small hydrogen concentration .The solutions having $\mathrm{pH}$ value of 7 are neutral solutions. In this process we can detect the $\mathrm{pH}$ levels in the soil.

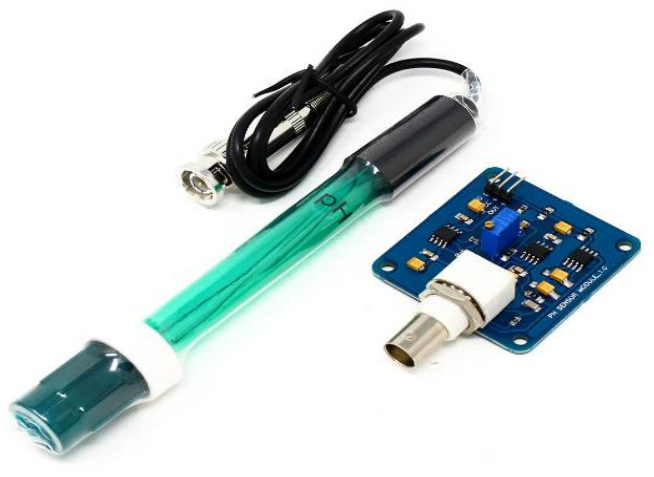

Fig 5: Ph Sensor

Based on the values of PH, its plant's growth will depends as follows:

Table-I shows the pH values and its plants growth

\begin{tabular}{|c|c|}
\hline Soil pH & Plant Growth \\
\hline$>8.3$ & Too alkaline for most plants \\
\hline 7.5 & $\begin{array}{c}\text { Iron availability becomes a problem } \\
\text { on alkaline soils. }\end{array}$ \\
\cline { 1 - 1 } 7.2 & $\begin{array}{c}6.8 \text { to } 7.2-\text { near neutral } \\
\text { to } 7.5-\text { acceptable for most } \\
\text { plants }\end{array}$ \\
\cline { 1 - 1 } 7.0 & Reduced soil microbial activity \\
\hline 6.8 & Too acidic for most plants \\
\hline 5.5 & \\
\hline
\end{tabular}

\section{Color sensor}

Color sensor is used to identify the color of various components, minerals present in the earth surface and inside of the earth. This sensor detects color usually in RGB scale. RGB scale is a combination of red, Green and blue colors. Each color has its unique wavelength. Combination of these colors at different properties creates different colors. These sensors also contain filters to avoid unwanted UV and IR light[5].

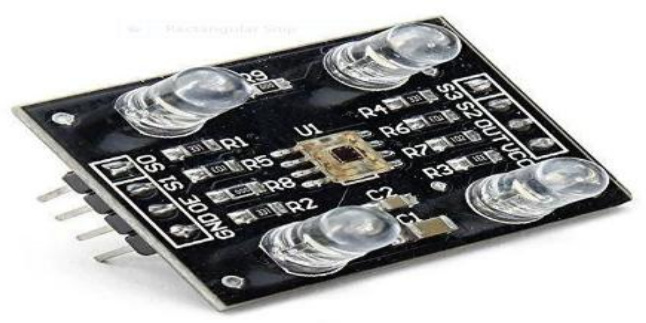

Fig 6: Color Sensor

\section{SYSTEM METHODOLOGY}

\section{A. Algorithm}

Below are the steps to be followed:

Step 1: Start

Step 2: Entire Project kit placed near the crop field

Step 3: Sensors senses and gives the accurate measures

Step 4: Values send to Arduino Uno

Step 5: All Data sends to the server

Step 6: Suitable crop and its NPK values on Farmers mobile.

Step 7: Stop

\section{B. Flowchart}

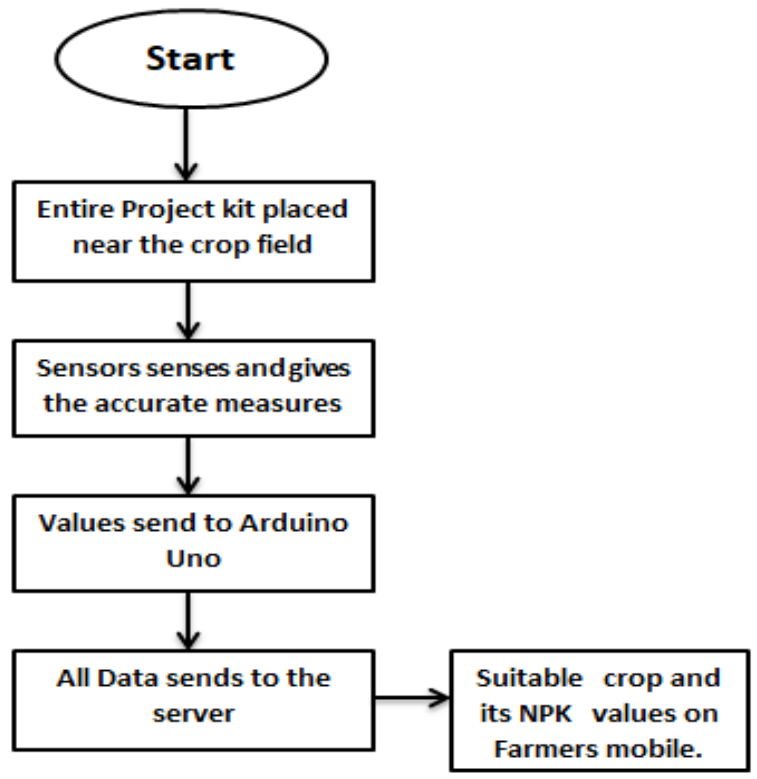

Fig 7: Flow of system operation

\section{EXPERIMENT AND ITS RESULT}

This project is interconnected with both hardware and software. The hardware consists of Arduino Uno with an inbuilt Microcontroller, Moisture sensor, DHT11 sensor, PH sensor, and GSM module whereas software includes Embedded ' $\mathrm{C}$ ', Eagle software for PCB designing. Then we will connect the components to the Arduino Uno. The power supply will be automatically supplied from the Arduino Uno of 5V. Also, connect the Arduino Uno to GSM Module to deliver the SMS for the Farmer. After ensuring that the given connections are correct, then its corresponding code will be dump into the microcontroller so that the dumped code won't get erased until and unless another code will get dumped. Thus, the accurate results will be displayed on the LCD as well as message will convey to the farmer accordingly.

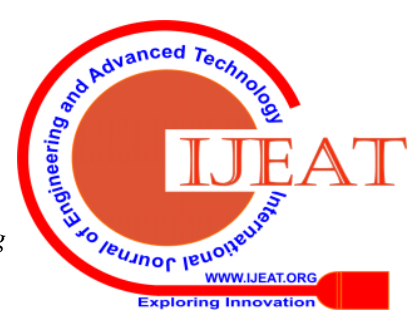




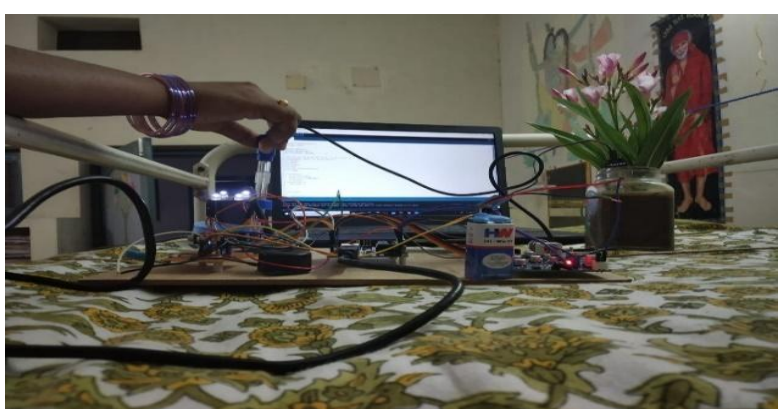

Figure 8(a): Experimentation of this project

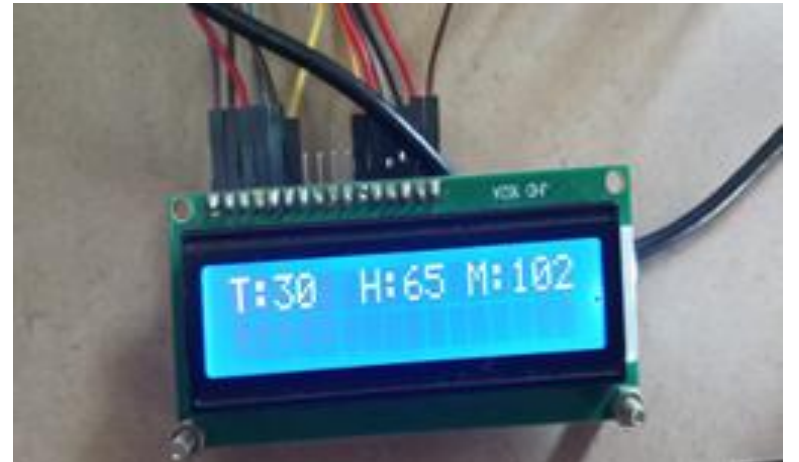

Figure 8(b): Output readings of Temperature Humidity and Moisture content of the soil

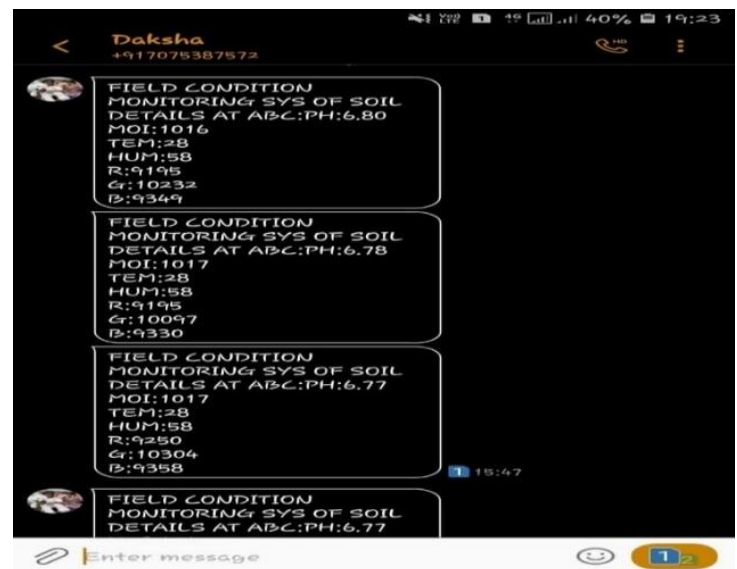

Fig 8(c): Updated information to the farmers via; SMS.

\section{ADVANTAGES}

- $\quad$ Livestock monitoring.

- Monitoring climate conditions.

- Greenhouses automation.

- Crop monitoring.

- Farm management systems.

\section{DISADVATAGES}

$>$ As this project runs with the Internet connection, there is no availability of proper internet connections in the villages.

$>$ In spite of using this there are many technologies, automated robots in the farms, land rollers with the best technologies.

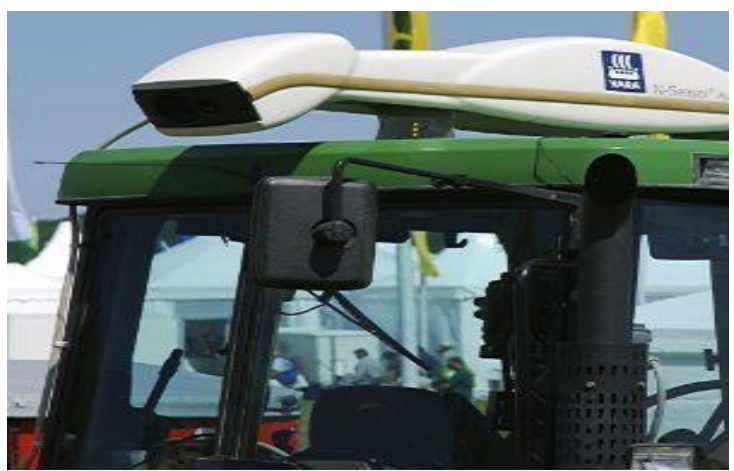

Figure: Modernized Agriculture system

\section{APPLICATIONS}

$>$ Maintaining green houses and soil monitoring.

$>$ Crop maintenance.

\section{CONCLUSION}

Thus, the IOT based farming are very helpful for the farmers for getting the updated information. Meanwhile, Farmers and landowners must know the potential of IOT in the market currently. The demand also rapidly increases if we use IOT technology in a proper manner.

\section{REFERENCES}

1. Agarwal, R. and Karahanna, E. Time flies when you're having fun:Cognitive absorption and beliefs about information technology usage, MIS Quarterly, vol. 24, no. 4, pp. 665-694, 2000.

2. G.V. Satyanarayana , S D. Mazaruddin, "Wireless Sensor Based RemoteMonitoring System for Agriculture using ZigBee and GPS", Conference onAdvances in Communication and Control Systems, 2013.

3. Fanuhs asefaw aregay and Zhoo minjipum "Impact of irrigation onFertilizer Use Decision of Farmers", journal of sustainable developmentvolume5 number4 april 2012.

4. Nikes Gondchawar , R. S. Kawitkar, "IOT based Smart Agriculture",International Journal of Advanced Research in Computer and

Communication Engineering, vol. 5, no. 6, pp. 2278-1021, June 2016.

5. P.Rajalakshmi, S. Devi Mahalakshmi , "IOT Based CropFieldMonitoring And Irrigation Automation" in 10th International conference on Intelligent systems and control (ISCO) 7-8 Jan 2016, published in IEEEXplore, Nov 2016.

6. D Ramesh, B. Vishnu Vardhan, "Data Mining Techniques and Applications to Agricultural Yield Data", International Journal of Advanced Research in Computer and Communication Engineering, Vol. 2, Issue 9, September 2013.

7. Meghali A. Kalyankar, S.J.Alaspurkar, "Data Mining Technique to Analyze the Metrological Data", Research Paper in International Journal of Advanced Research in Computer Science and Software Engineering.

8. Sumitha Thankachan, S. Kirubakaran, "E-Agriculture Information Management System", International Journal of Advanced Research in Computer Science and Software Engineering, Volume 3, Issue 2, February 2013.

9. Aqueel-ur-Rehman, Abu Zafar Abbasi, Noman Islam, Zubair Ahmed Shaikh, "A review of wireless sensor and networks applications in agriculture", Computer Standards \& Interfaces 36(2014) 263- 270.

10. Sally Jo Cunningham, Geoffrey Holmes, "Developing innovative applications in agriculture using data mining", SEARCC'99 conference proceedings.

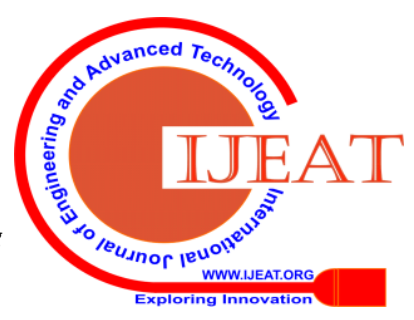




\section{AUTHORS PROFILE}

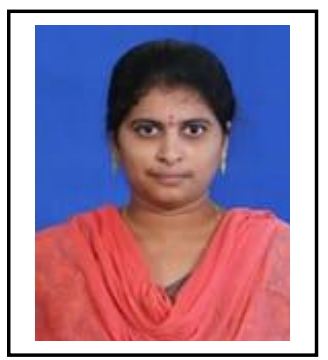

Asadi Mutyalamma: working as Assistant Professor in the Department of Electronics and Communication Engineering, Bapatla Women's Engineering college, Bapatla. Received M.Tech degree in the area of VLSI from KL University in 2015 and B.tech degree from JNTUH in 2013.Presently working research in the area of IOT applications.

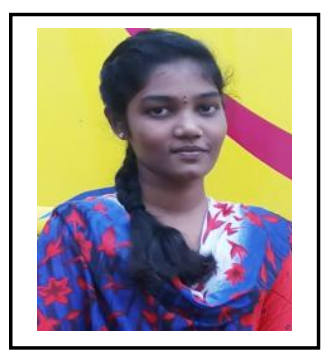

Gopisetty Yoshitha: Iam a student of Bapatla Women's Engineering College studying final year belongs to department of Electronics and Communication Engineering, B.Tech. I have done my specialization in Internet of Things. I worked on the one of the application of IoT as my Project.

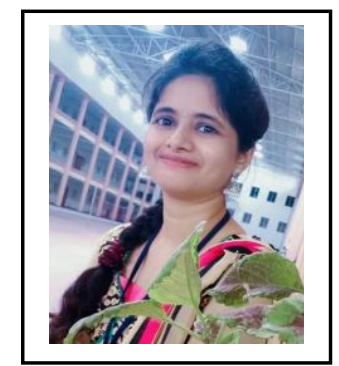

Althi Dakshyani: Iam a student of Bapatla Women's Engineering College studying final year belongs to department of Electronics and Communication Engineering, B.Tech. I have done my specialization in Internet of Things. I worked on the one of the application of IoT as my Project

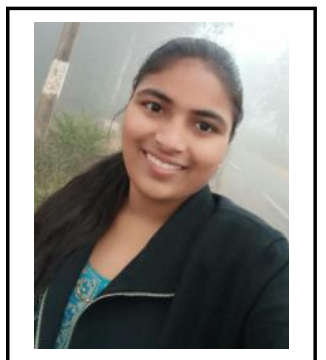

BachalaVenkata Padmavathi: Iam a student of Bapatla Women's Engineering College studying final year belongs to department of Electronics and Communication Engineering, B.Tech. I have done my specialization in Internet of Things. I worked on the one of the application of IoT as my Project.

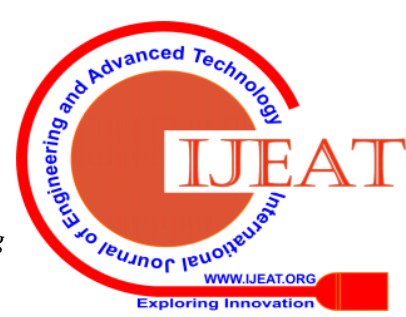

